\title{
Comparison of High-Resolution MR Imaging and Digital Subtraction Angiography for the Characterization and Diagnosis of Intracranial Artery Disease
}

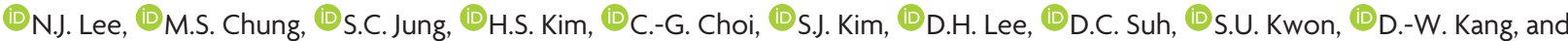 \\ (D).S. Kim

\begin{abstract}
BACKGROUND AND PURPOSE: High-resolution MR imaging has recently been introduced as a promising diagnostic modality in intracranial artery disease. Our aim was to compare high-resolution MR imaging with digital subtraction angiography for the characterization and diagnosis of various intracranial artery diseases.
\end{abstract}

MATERIALS AND METHODS: Thirty-seven patients who had undergone both high-resolution MR imaging and DSA for intracranial artery disease were enrolled in our study (August 2011 to April 2014). The time interval between the high-resolution MR imaging and DSA was within 1 month. The degree of stenosis and the minimal luminal diameter were independently measured by 2 observers in both DSA and high-resolution MR imaging, and the results were compared. Two observers independently diagnosed intracranial artery diseases on DSA and high-resolution MR imaging. The time interval between the diagnoses on DSA and high-resolution MR imaging was 2 weeks. Interobserver diagnostic agreement for each technique and intermodality diagnostic agreement for each observer were acquired.

RESULTS: High-resolution MR imaging showed moderate-to-excellent agreement (interclass correlation coefficient $=0.892-0.949 ; \kappa=$ $0.548-0.614)$ and significant correlations $(R=0.766-892)$ with DSA on the degree of stenosis and minimal luminal diameter. The interobserver diagnostic agreement was good for DSA $(\kappa=0.643)$ and excellent for high-resolution MR imaging $(\kappa=0.818)$. The intermodality diagnostic agreement was good $(\kappa=0.704)$ for observer 1 and moderate $(\kappa=0.579)$ for observer 2 , respectively.

CONCLUSIONS: High-resolution MR imaging may be an imaging method comparable with DSA for the characterization and diagnosis of various intracranial artery diseases.

ABBREVIATIONS: HR-MR = high-resolution MR imaging; ICAD = intracranial artery disease; ICC = interclass correlation coefficient

ntracranial artery disease (ICAD) is one of the major causes of ischemic stroke and neurologic symptoms. ${ }^{1-3}$ ICAD generally presents with intracranial artery stenosis on luminal evaluation, even though it includes various ICADs, such as atherosclerosis,

Received April 7, 2016; accepted after revision July 22.

From the Department of Radiology and Research Institute of Radiology (N.J.L., M.S.C., S.C.J., H.S.K., C.-G.C., S.J.K., D.H.L., D.C.S.) and Department of Neurology (S.U.K., D.-W.K., J.S.K.), University of Ulsan College of Medicine, Asan Medical Center, Seoul, Korea.

The authors declare no relationships with any companies whose products or services may be related to the subject matter of the article.

This work was supported by a grant from the Korea Healthcare Technology R\&D Project, Ministry for Health, Welfare, and Family Affairs, Republic of Korea (HII2C1847).

Paper previously presented orally at: Annual Meeting of the European Congress of Radiology, March 2-6, 2016; Vienna, Austria.

Please address correspondence to Seung Chai Jung, MD, PhD, Department of Radiology and Research Institute of Radiology, University of Ulsan College of Medicine, Asan Medical Center, 86 Asanbyeongwon-Gil, Songpa-Gu, Seoul 138-736, Republic of Korea; e-mail: dynamics79@gmail.com

- Indicates open access to non-subscribers at www.ajnr.org

Indicates article with supplemental on-line photo.

http://dx.doi.org/10.3174/ajnr.A4950 dissection, Moyamoya disease, and vasculitis. The degree of stenosis has been the most common and important characteristic for evaluating ICAD and determining the treatment options. ${ }^{4,5}$

Luminal angiography, such as digital subtraction angiography, CT angiography, and MR angiography, has been widely used and has functioned successfully for the evaluation of stenosis and the diagnosis of ICAD. Among these methods, DSA is thought to be the criterion standard tool compared with the other modalities because it depicts luminal geometric shapes and hemodynamic information with higher resolution. ${ }^{6-8}$ However, DSA has several limitations. It only depicts the luminal morphology and not the vessel walls directly, and many diseases share nonspecific luminal findings. Because DSA is also an invasive procedure with the risk of neurologic complications and radiation exposure, it is not suitable for screening or serial examinations. ${ }^{9-11}$ Accordingly, CTA and MRA have been commonly used as the minimally invasive method to diagnose and differentiate intracranial artery disease in the clinical field, though they have more drawbacks in the luminal evaluation to DSA. 
High-resolution MR imaging (HR-MR) has recently been introduced as a minimally invasive and promising advanced imaging technique for directly depicting the intracranial arterial wall. ${ }^{12,13}$

Although HR-MR evaluates and differentiates various ICADs with the direct depiction of arterial walls and multicontrast images $^{6,14-20}$ that may correlate with luminal angiography, ${ }^{8,21,22}$ the usefulness and value of HR-MR compared with luminal angiography are still unclear. Only a few studies presented a comparison or correlation between DSA and HR-MR, ${ }^{8,13,23}$ and these studies showed a good correlation regarding the degree of stenosis ${ }^{8,23}$ and HR-MR features beyond DSA. ${ }^{13}$ However, the observations were based on single vascular pathology or a single cerebral artery (middle cerebral artery, basilar artery) or a small sample size $(n=9)$.

In our study, we compared HR-MR with DSA in the characterization and diagnosis of various ICADs. We hypothesized that HR-MR may be an imaging method comparable with DSA for the characterization and diagnosis of ICAD.

\section{MATERIALS AND METHODS}

This retrospective study was approved by our institutional review board, and patient informed consent was waived. The stipulation regarding obtaining informed consent from study patients was waived. Patient information was anonymized and de-identified before the assessment.

\section{Patients}

From August 2011 to April 2014, 79 patients underwent both DSA and HR-MR in our hospital. Of them, 42 patients were excluded because the imaging was performed for aneurysms and extracranial artery disease and had time intervals beyond 1 month between the 2 imaging methods. Finally, 37 patients were retrospectively enrolled. These patients were admitted to our hospital with intracranial artery disease. DSA and HR-MR were performed within 1 month. There were 18 male and 19 female patients with a mean age of 51 years (range, 17-74 years of age); 44 intracranial arteries were included in our study. These included the middle cerebral artery $(n=31)$, vertebral artery $(n=7)$, basilar artery $(n=2)$, internal carotid artery $(n=1)$, anterior cerebral artery $(n=1)$, posterior inferior cerebellar artery $(n=1)$, and multiple cerebral arteries $(n=1)$. Seven patients had bilateral middle cerebral artery disease. The patients were admitted with ischemic symptoms $(n=21)$, headache or neck pain $(n=8)$, dizziness $(n=$ $4)$, headache with ischemia $(n=3)$, and no symptoms $(n=1)$.

\section{Imaging Protocol}

HR-MR was performed with 3D proton-density imaging and 2D proton-density, T1-weighted, T2-weighted, and contrast-enhanced T1-weighted imaging with planes perpendicular to the arterial course by using a 3T scanner with an 8-channel head coil (Achieva; Philips Healthcare, Best, the Netherlands). The 3D proton-density imaging with turbo spin-echo sequences was performed with the following parameters: TR, $2000 \mathrm{~ms}$; TE, $30.7 \mathrm{~ms}$; flip angle, $90^{\circ}$; matrix, $640 \times 640$; FOV , $180 \times 180 \mathrm{~mm}$; section thickness, $0.6 \mathrm{~mm}$; and NEX, 1 . The $2 \mathrm{D}$ proton-density imaging was performed on the basis of turbo spin-echoes. The protocols for proton-density imaging were as follows: TR, $2000 \mathrm{~ms}$; TE, 32.7 $\mathrm{ms}$; flip angle, $90^{\circ}$; matrix, $336 \times 336$; FOV, $100 \times 100 \mathrm{~mm}$; section thickness, $1 \mathrm{~mm}$; NEX, 2. For T1-weighted imaging, the parameters were as follows: TR, $1533.2 \mathrm{~ms}$; TE, $8.4 \mathrm{~ms}$; flip angle, $90^{\circ}$; matrix, $512 \times 512$; FOV, $100 \times 100 \mathrm{~mm}$; section thickness, 1 $\mathrm{mm}$; NEX, 2. For T2-weighted imaging, the parameters were as follows: TR, $3178.2 \mathrm{~ms}$; TE, $80 \mathrm{~ms}$; flip angle, $90^{\circ}$; matrix, $512 \times$ 512; FOV , $100 \times 100 \mathrm{~mm}$; section thickness, $1 \mathrm{~mm}$; and NEX, 4 . Contrast-enhanced T1-weighted imaging was performed after intravenous administration of gadoterate meglumine (Dotarem; Guerbet, Aulnay-sous-Bois, France) at a dose of $0.1 \mathrm{mmol} / \mathrm{kg}$ of body weight.

DSA was performed in 4 vessels by using a biplane system, including high-resolution 3D rotational angiography (Artis zee; Siemens, Erlangen, Germany). Transfemoral access was used, and selective injection of contrast medium, iodixanol (320 mg of iodine/mL, Visipaque; GE Healthcare, Piscataway, New Jersey), was performed at a rate of $2.5 \mathrm{~mL}$ per second by using an injector (Mark V ProVis; Medrad, Medrad, Indianola, Pennsylvania). The parameters were as follows: matrix, 1024 or 2048; FOV, $320 \mathrm{~mm}$.

\section{Imaging Analysis}

The degree of stenosis and the minimal luminal diameter of an ICAD were independently measured by 2 observers on the basis of the PACS workstation and in-house analysis software based on ImageJ, a public domain, Java-based image-processing program developed at the National Institutes of Health, Bethesda, Maryland, for both DSA and HR-MR. The measurement was performed on the basis of the manual thresholding. The degree of stenosis was assessed on the basis of the Warfarin-Aspirin Symptomatic Intracranial Disease (WASID) trial ${ }^{24}$ by measuring the diameter of the residual lumen at the maximal narrowing site by using the formula [ 1 - (diameter of stenosis / diameter of normal) $\times 100$ ] (Fig 1). The normal arterial luminal diameter was measured distal or proximal to the maximal narrowing site. ${ }^{25}$ The minimal luminal diameter referred to the measurement at the maximal narrowing site. The degree of stenosis was classified into 3 groups: $<50 \%, 50 \%-70 \%$, and $>70 \%$. In the measurements, 4 arteries were excluded because they were not steno-occlusive lesions (ie, normal variation, aneurysm).

\section{Diagnosis}

Two neuroradiologists independently diagnosed various ICADs on DSA and HR-MR. The clinical information, such as patient age, sex, symptoms, onset of symptoms, examination date of DSA and HR-MR, medical background (ie, hypertension; diabetes mellitus; hyperlipidemia; smoking; alcohol; previous medical history, including heart disease, stroke, trauma, and medication; laboratory findings including hemoglobin Alc, lipid battery, blood pressure, homocysteine, and body mass index), and the number of vascular risk factors for atherosclerosis, was provided to the observers. DSA and HR-MR were respectively reviewed with a 2 -week interval for prevention of recall bias. Interobserver agreement for each technique was respectively obtained. For each observer, intermodality agreement was acquired respectively, and agreement and disagreement between the 2 modalities were analyzed. 


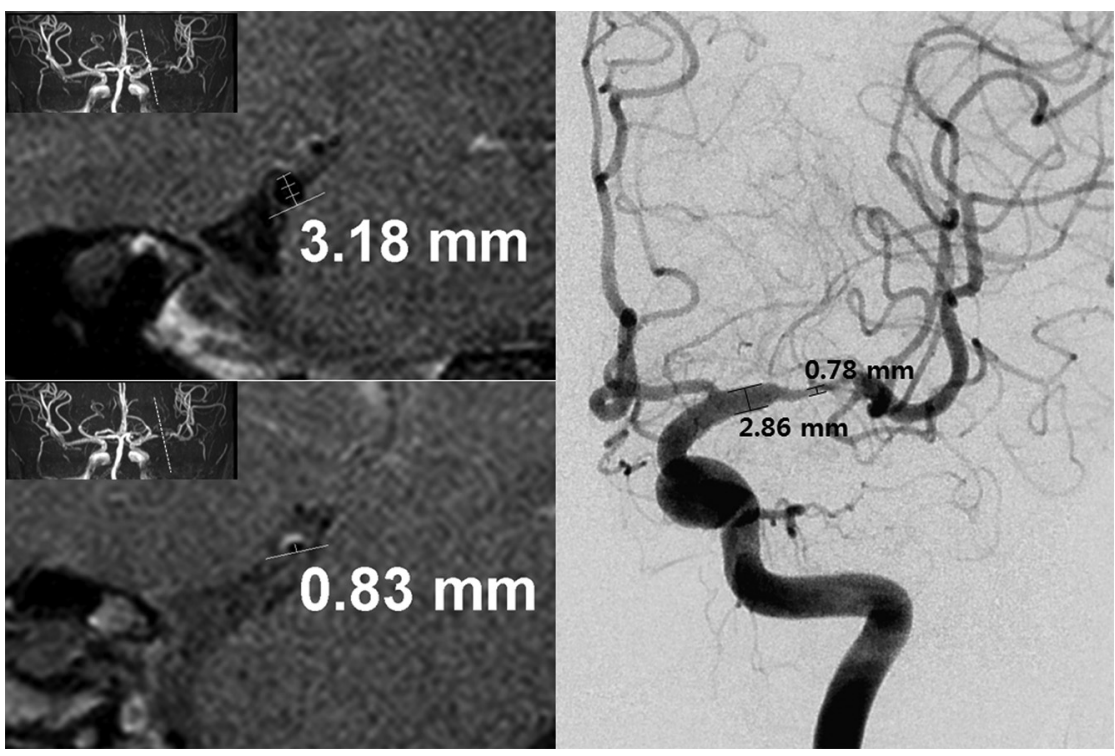

FIG 1. Measurements of the degree of stenosis and minimal luminal diameter in both DSA and HR-MR. The degree of stenosis is $73.9 \%$ on HR-MR (normal luminal diameter, $3.18 \mathrm{~mm}$; minimal luminal diameter, $0.83 \mathrm{~mm}$ ) and $72.7 \%$ on DSA (normal luminal diameter, $2.86 \mathrm{~mm}$; minimal luminal diameter, $0.78 \mathrm{~mm}$ ).

\section{Atherosclerosis}

Atherosclerosis was diagnosed according to the following criteria: 1) radiologic findings: atherosclerotic stenosis or occlusion (DSA) and eccentric wall thickening (HR-MR) of arteries in the corresponding vascular territory of acute infarction; 2) clinical findings: $\geq 2$ vascular risk factors according to patient age (men older than 50 years, women older than 60 years), hypertension, diabetes mellitus, hyperlipidemia, obesity, and smoking; and 3) exclusion criteria: cardioembolism, $>50 \%$ stenosis of extracranial arteries proximal to the symptomatic intracranial stenosis, nonatherosclerotic vasculopathy such as vasculitis, or Takayasu arteritis. ${ }^{15,26}$

\section{Dissection}

Dissection was classified as a definite or suspected case according to the Strategies against Stroke Study for Young Adults in Japan criteria. ${ }^{27}$ Intimal flap and double lumen were considered definite dissection findings. Suspected dissection included the string of pearls sign, tapered occlusion (DSA), intramural hematoma, and aneurysmal dilation (HR-MR). ${ }^{27}$

\section{Moyamoya Disease}

Moyamoya disease is defined as stenosis or occlusion at the terminal portions of the internal carotid artery or the proximal portions of the anterior or middle cerebral artery with abnormal vascular networks. ${ }^{28-31}$ According to the guidelines of the Research Committee on Spontaneous Occlusion of the Circle of Willis, Moyamoya disease was classified as definite Moyamoya disease with bilateral lesions or probable Moyamoya syndrome with a unilateral lesion. ${ }^{30,31}$ For HR-MR, we added the following diagnostic criteria: severe decrease in the outer diameter relative to the normal artery, thin vessel wall, and mild and diffuse concentric enhancement. ${ }^{15,18}$

\section{Vasculitis}

Vasculitis is diagnosed in an exclusive process considering its clinical and radiologic features. Therefore, there is no definite evidence of the presence of other intracranial artery diseases, including atherosclerosis, dissection, and Moyamoya disease. Alternating lesions of stenosis, dilation, and occlusion were suggested as the classic DSA features. ${ }^{32}$ Smooth and concentric wall thickening with enhancement in the involved vessels was considered the HR-MR feature. ${ }^{17,19,26,33}$

\section{Miscellaneous Diagnoses}

In patients with DSA or HR-MR demonstrating hypoplasia, fenestration, and a tortuous course of the normal artery, normal variation was diagnosed. Localized and blood-filled outward bulging of the arterial wall without a vessel arising from the apex and with surrounding hemorrhage was diagnosed as a ruptured aneurysm.

\section{Undetermined Diagnosis}

When a patient could not be diagnosed on the basis of the aforementioned criteria, the diagnosis was classified as undetermined.

\section{Statistical Analysis}

Commercially available software (MedCalc for Windows, Version 11.1.1.0; MedCalc Software, Mariakerke, Belgium) was used for the analysis. The Kolmogorov-Smirnov test was used to determine whether the values were normally distributed. For all statistical analyses, a 2 -tailed $P$ value $<.05$ was considered indicative of a statistically significant difference. The degree of stenosis and minimal luminal diameter were compared by using the paired Wilcoxon signed rank test, and interobserver agreement was assessed by using the interclass correlation coefficient (ICC). Intermodality agreement regarding the measurements between DSA and HR-MR was assessed by using the ICC (continuous values) and Cohen $\kappa$ (classified stenosis groups, $<50 \%, 50 \%-70 \%,>70 \%$ ), and the Spearman $R$ was calculated regarding the relationship between DSA and HRMR. Interobserver and intermodality diagnostic agreement regarding ICAD was analyzed by using the Cohen $\kappa$. The proportions of undetermined diagnoses were compared between DSA and HR-MR by using the McNemar test. The strength of agreement of the ICC and $\kappa$ values was categorized as follows: $<0.20$, poor; $0.21-0.40$, fair; $0.41-0.60$, moderate; $0.61-0.80$, good; and 0.81-1.00, excellent.

\section{RESULTS}

\section{Comparison of the Degree of Stenosis and the Minimal Luminal Diameter}

The information about the degree of stenosis and the minimal luminal diameter is presented in Table 1. The minimal luminal

AJNR Am J Neuroradiol 37:2245-50 Dec 2016 www.ajnr.org 
Table 1: Comparison of the degree of stenosis and the minimal luminal diameter

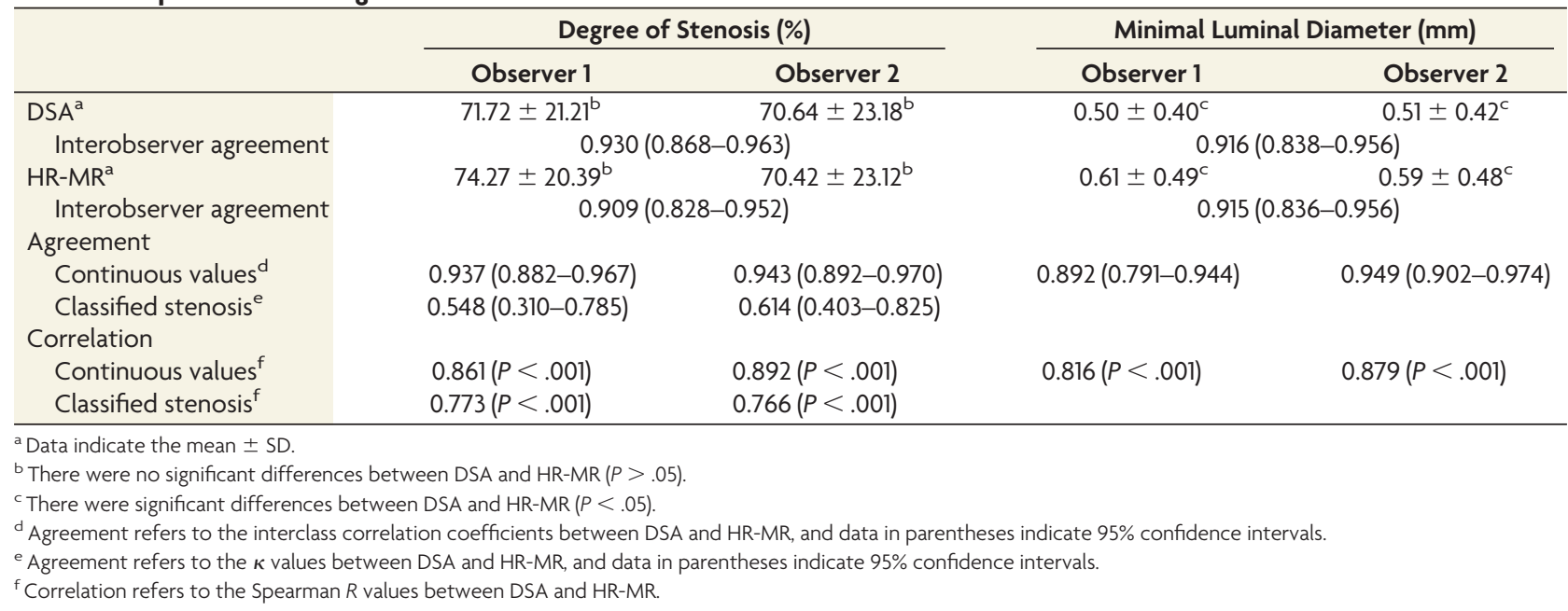

Table 2: Interobserver and intermodality diagnostic agreement

\begin{tabular}{lcccc}
\hline & $\begin{array}{c}\text { Diagnostic } \\
\text { Agreement }^{\mathbf{a}}\end{array}$ & $\begin{array}{c}\text { Agreement } \\
\text { Ratio }^{\text {b }}\end{array}$ & $\begin{array}{c}\text { Disagreement } \\
\text { Ratio }^{\mathrm{b}}\end{array}$ & $\begin{array}{c}\text { Undetermined } \\
\text { Diagnosis }^{{ }^{c}}\end{array}$ \\
\hline DSA $^{\mathrm{d}}$ & $0.643(0.458-0.828)$ & $73.0 \%(27 / 37)$ & $27.0 \%(10 / 27)$ & $5.41 \% / 16.22 \%$ \\
HR-MR $^{\mathrm{d}}$ & $0.818(0.670-0.966)$ & $86.5 \%(32 / 37)$ & $13.5 \%(5 / 37)$ & $2.70 \% / 5.41 \%$ \\
Observer 1 $^{\mathrm{e}}$ & $0.704(0.528-0.881)$ & $78.4 \%(29 / 37)$ & $21.6 \%(8 / 37)$ & \\
Observer 2 $^{\mathrm{e}}$ & $0.579(0.390-0.768)$ & $67.6 \%(25 / 37)$ & $32.4 \%(12 / 37)$ & \\
\hline
\end{tabular}

${ }^{a}$ Agreement refers to $\kappa$ values between DSA and HR-MR, and data in parentheses indicate $95 \%$ confidence intervals.

${ }^{b}$ Data in parentheses indicate the numbers of agreed or disagreed cases compared with the total number of cases in the diagnosis.

c The proportions of undetermined diagnosis for observer 1 /observer 2 .

${ }^{\mathrm{d}}$ Interobserver agreement between observer 1 and observer 2 .

e Intermodality agreement between DSA and HR-MR.

diameter had a significant difference $(P=.026, .014)$, whereas the degree of stenosis did not have a significant difference $(P=.070$, 0.708 ) between DSA and HR-MR. Interobserver agreement for the measurements was excellent (ICC $=0.909-0.930)$. Intermodality agreement for the measurements was excellent (ICC = $0.937-0.943)$; moderate to good $(\kappa=0.548-0.614)$ for the degree of stenosis; and excellent (ICC $=0.892-0.949$ ) for the minimal luminal diameter. The correlation coefficients were $0.766-0.892$ (Spearman $R, P<.001$ ) for the degree of stenosis and $0.816-0.879$ (Spearman $R, P<.001$ ) for the minimal luminal diameter.

\section{Comparison of Diagnoses}

Interobserver Diagnostic Agreement. On DSA images, both observers agreed as to the diagnosis in 27 of the 37 the patients (73.0\%), and the interobserver diagnostic agreement was good ( $\kappa=0.643 ; 95 \%$ confidence interval, $0.458-0.828$ ). For HR-MR, 2 observers were in agreement with regard to the diagnosis of ICAD in 32 of the 37 patients (86.5\%), thus resulting in excellent agreement $(\kappa=0.818$; 95\% confidence interval, $0.670-0.966$ ) (Table 2 and On-line Figure).

Intermodality Diagnostic Agreement. For the diagnoses for DSA and HR-MR, there was agreement in 29 of the 37 patients (78.4\%) and disagreement in 8 patients $(21.6 \%)$ for observer 1. For observer 2, in 25 of the 37 patients $(67.6 \%)$, there was agreement in the diagnoses, and in 12 patients (32.4\%), there was disagreement. There was also good and moderate agreement between the 2 imaging modalities with $\kappa$ values of 0.704
(95\% confidence interval, $0.528-$ $0.881)$ and 0.579 (95\% confidence interval, $0.390-0.768)$, respectively. The percentages of undetermined diagnoses did not show significant differences between DSA and HR-MR, even though HR-MR showed lower percentages than DSA (observer 1: 5.41\% versus $2.70 \%, P=1.000$; observer 2 : $16.22 \%$ versus $5.41 \%, P=.125$ ) (Table 2 and On-line Figure).

\section{DISCUSSION}

In our study, HR-MR showed greater than or equal to moderate agreement (ICC $=0.892-0.949 ; \kappa=0.548-0.614)$ and significant correlations (Spearman $R=0.766-0.892, P<.001$ ) with DSA regarding the degree of stenosis and the minimal luminal diameter. There was no significant difference in the degree of stenosis, whereas the minimal luminal diameter was significantly higher on HR-MR than on DSA. Both interobserver diagnostic agreements were higher on HR-MR than on DSA. The percentages of undetermined diagnoses were similar on HR-MR compared with DSA. HR-MR may, therefore, be a useful imaging option comparable with DSA for the characterization of stenosis and the diagnosis of various ICADs.

Although many studies have reported the diagnostic usefulness of HR-MR, they focused on the radiologic findings of pathologic vessel walls for the diagnosis or differentiation of ICADs. ${ }^{3,15-17,21,34,35}$ However, those studies lacked information regarding the comparison between luminal angiography and HR-MR, which may lead to disputes and confusion regarding the usefulness of HR-MR as an imaging method. Only a few studies have attempted to reveal the usefulness of HR-MR compared with DSA. ${ }^{8,13,18,23}$ However, these observations were limited regarding only single vascular pathology (atherosclerosis, Moyamoya disease) or single cerebral artery (middle cerebral artery, basilar artery) or the small patient sample size $(n=9)$. In particular, although these studies acknowledged that HR-MR presents additional information, such as the direct depiction of vessel walls beyond the luminal evaluation, HR-MR was evaluated 
by using DSA as the reference standard. We performed an independent evaluation and diagnosis for each technique and compared DSA and HR-MR in various ICADs with the largest patient populations in all of the published studies, to our knowledge.

Liu et $\mathrm{al}^{8}$ showed a significant correlation (Spearman $R=0.68$; $P<.01)$ and no significant difference $(P>.05)$ in the degree of stenosis detected by both DSA and HR-MR. Our study also demonstrated the significant correlation (Spearman $R=0.766-$ 0.892; $P<.001)$ without a significant difference $(P>.05)$ in the degree of stenosis. Our results also included the significant correlation (Spearman $R=0.816-879 ; P<.001$ ) in the minimal luminal diameter. Liu et al only evaluated the degree of stenosis in the middle cerebral artery, whereas our results were based on various intracranial arteries, which may contribute to a wide application of HR-MR with its results comparable with those of DSA.

The degree of stenosis did not have a significant difference between DSA and HR-MR, whereas the minimal luminal diameter measured significantly higher in HR-MR than in DSA (0.50-0.51 versus $0.59-0.61$ ). The discrepancy may suggest the overestimation of the luminal diameter on HR-MR or the underestimation on DSA. According to the previously mentioned studies, DSA may underestimate the diameter of intracranial arteries due to its limited number of projections. ${ }^{36,37}$ Of 80 arteries (both observers 1 and 2), $18 \mathrm{dem}$ onstrated a discrepancy in the classification of the stenosis $(<50 \%$, $50 \%-70 \%,>70 \%$ ) between DSA and HR-MR. However, of those arteries, 15 showed that the differences from the margins of the degree of stenosis ( $50 \%$ or $70 \%$ ) were within $5 \%$; thus, the discrepancy may be within the measurement error.

Katsuno and Kobayashi ${ }^{38}$ compared the diagnoses of DSA and basiparallel anatomic scanning MR imaging, showing only the outer lumen of the vessels, in 22 patients with severe headache and neck pain. They focused on dissection and atherosclerosis, which had good agreement ( $\kappa=0.636$; 95\% confidence interval, $0.314-$ 0.959 ) between DSA and basiparallel anatomic scanning MR imaging. ${ }^{38}$ In this study, the intermodality diagnostic agreement was $0.579-0.704$, even in various ICADs.

In our study, HR-MR showed higher interobserver diagnostic agreement and lower proportions of undetermined diagnosis than DSA. Although the higher interobserver diagnostic agreement and the lower proportions of undetermined diagnoses were unclear as to their statistical significance and may not indicate higher diagnostic performance, HR-MR may not only be a useful imaging technique regarding the diagnosis but may also contribute to solving problem cases on luminal angiography due to the additional information beyond the luminal characterization. Hui et $\mathrm{al}^{13}$ also postulated that DSA is inferior to HR-MR in vessel wall evaluation, though stenosis and occlusion may appear similar in all kinds of ICADs. Although DSA is still the criterion standard in ICAD, other types of luminal angiography, such as CTA and MRA with their minimal invasiveness, have widened the scope because DSA is an invasive study with complication risks, including morbidity and mortality. ${ }^{8-10}$ However, we should be concerned about the balance between the risks of an incorrect diagnosis and the association with an imaging procedure. HR-MR is a minimally invasive imaging technique that showed superior diagnostic performance over CTA or MRA. ${ }^{8,21}$ Therefore, HR-MR may be an alternative to luminal angiography for both characterization and diagnosis.

DSA can present hemodynamic information and anatomic luminal changes, whereas HR-MR can offer direct anatomic information regarding a vascular wall or plaque as well as luminal change. In addition, parenchymal information regarding the area corresponding to the vascular abnormality can be demonstrated by HR-MR. ${ }^{12}$ Therefore, HR-MR may present information different from that of DSA, allowing it to function as a comparable imaging method with different indications in ICAD.

Our study has a number of limitations. First, it was a retrospective study and enrolled only a small number of patients, which may result in limitations in its statistical significance and selection bias. Second, we did not perform comparisons of HR-MR with 3D rotational angiography, which may be a solution to the discrepancies in the minimal luminal diameter and degree of stenosis. Third, the diagnoses in our study may be insufficient because they were made according to the aforementioned diagnostic criteria and the conclusive diagnosis with pathologic confirmation in ICAD was not acquired. Therefore, ICAD was usually diagnosed on the basis of the clinical, laboratory, and radiologic information without the pathologic confirmation, and physicians sometimes must diagnose challenging cases in the real clinical field. The enrolled patients were also challenging cases for both DSA and HR-MR, which may introduce a selection bias and result in an imbalance of analyzed arterial segments. However, we believe that our study substantially reflects actual clinical practice despite these limitations. Fourth, there was no correlation with the treatment options or prognosis between DSA and HR-MR. We hope that our study contributes to further study regarding the comparisons between HR-MR and DSA as imaging methods used to guide treatment or prognosis.

\section{CONCLUSIONS}

HR-MR may be an imaging method comparable with DSA in the characterization and diagnosis of various ICADs.

Disclosures: Seung Chai Jung-RELATED: Grant: Korea Healthcare Technology R\&D Project, Ministry for Health, Welfare, and Family Affairs, Republic of Korea (HI12C1847). Sun U. Kwon-UNRELATED: Grants/Grants Pending: Korea Healthcare Technology R\&D Project, Ministry of Health and Welfare, Republic of Korea (HI10C2020).* * Money paid to the institution.

\section{REFERENCES}

1. Bang OY. Intracranial atherosclerosis: current understanding and perspectives. J Stroke 2014;16:27-35 CrossRef Medline

2. Sacco RL, Boden-Albala B, Gan R, et al. Stroke incidence among white, black, and Hispanic residents of an urban community: the Northern Manhattan Stroke Study. Am J Epidemiol 1998;147: 259-68 CrossRef Medline

3. Li ML, Xu WH, Song L, et al. Atherosclerosis of middle cerebral artery: evaluation with high-resolution MR imaging at 3T. Atherosclerosis 2009;204:447-52 CrossRef Medline

4. Warfarin-Aspirin Symptomatic Intracranial Disease (WASID) Trial Investigators. Design, progress and challenges of a double-blind trial of warfarin versus aspirin for symptomatic intracranial arterial stenosis. Neuroepidemiology 2003;22:106-17 CrossRef Medline

5. Chimowitz MI, Lynn MJ, Howlett-Smith H, et al; Warfarin-Aspirin Symptomatic Intracranial Disease Trial Investigators. Comparison of warfarin and aspirin for symptomatic intracranial arterial stenosis. N Engl J Med 2005;352:1305-16 CrossRef Medline 
6. Wang Y, Lou X, Li Y, et al. Imaging investigation of intracranial arterial dissecting aneurysms by using $3 \mathrm{~T}$ high-resolution MRI and DSA: from the interventional neuroradiologists' view. Acta Neurochir (Wien) 2014;156:515-25 CrossRef Medline

7. Leng X, Wong KS, Liebeskind DS. Evaluating intracranial atherosclerosis rather than intracranial stenosis. Stroke 2014;45:645-51 CrossRef Medline

8. Liu Q, Huang J, Degnan AJ, et al. Comparison of high-resolution MRI with CT angiography and digital subtraction angiography for the evaluation of middle cerebral artery atherosclerotic steno-occlusive disease. Int J Cardiovasc Imaging 2013;29:1491-98 CrossRef Medline

9. Kaufmann TJ, Huston J 3rd, Mandrekar JN, et al. Complications of diagnostic cerebral angiography: evaluation of 19,826 consecutive patients. Radiology 2007;243:812-19 CrossRef Medline

10. Chung TS, Joo JY, Lee SK, et al. Evaluation of cerebral aneurysms with high-resolution MR angiography using a section-interpolation technique: correlation with digital subtraction angiography. AJNR Am J Neuroradiol 1999;20:229-35 Medline

11. Soize S, Bouquigny F, Kadziolka K, et al. Value of 4D MR angiography at 3T compared with DSA for the follow-up of treated brain arteriovenous malformation. AJNR Am J Neuroradiol 2014;35: 1903-09 CrossRef Medline

12. Xu WH, Li ML, Niu JW, et al. Intracranial artery atherosclerosis and lumen dilation in cerebral small-vessel diseases: a high-resolution MRI study. CNS Neurosci Ther 2014;20:364-67 CrossRef Medline

13. Hui FK, Zhu X, Jones SE, et al. Early experience in high-resolution MRI for large vessel occlusions. J Neurointerv Surg 2015;7:509-16 CrossRef Medline

14. Mandell DM, Matouk CC, Farb RI, et al. Vessel wall MRI to differentiate between reversible cerebral vasoconstriction syndrome and central nervous system vasculitis: preliminary results. Stroke 2012; 43:860-62 CrossRef Medline

15. Kim YJ, Lee DH, Kwon JY, et al. High resolution MRI difference between moyamoya disease and intracranial atherosclerosis. Eur J Neurol 2013;20:1311-18 CrossRef Medline

16. Zhu XJ, Du B, Lou X, et al. Morphologic characteristics of atherosclerotic middle cerebral arteries on $3 \mathrm{~T}$ high-resolution MRI. AJNR Am J Neuroradiol 2013;34:1717-22 CrossRef Medline

17. Obusez EC, Hui F, Hajj-Ali RA, et al. High-resolution MRI vessel wall imaging: spatial and temporal patterns of reversible cerebral vasoconstriction syndrome and central nervous system vasculitis. AJNR Am J Neuroradiol 2014;35:1527-32 CrossRef Medline

18. Ryoo S, Cha J, Kim SJ, et al. High-resolution magnetic resonance wall imaging findings of Moyamoya disease. Stroke 2014;45: 2457-60 CrossRef Medline

19. Mossa-Basha M, Hwang WD, De Havenon A, et al. Multicontrast high-resolution vessel wall magnetic resonance imaging and its value in differentiating intracranial vasculopathic processes. Stroke 2015;46:1567-73 CrossRef Medline

20. Choi YJ, Jung SC, Lee DH. Vessel wall imaging of the intracranial and cervical carotid arteries. J Stroke 2015;17:238-55 CrossRef Medline

21. Kim YS, Lim SH, Oh KW, et al. The advantage of high-resolution MRI in evaluating basilar plaques: a comparison study with MRA. Atherosclerosis 2012;224:411-16 CrossRef Medline
22. Qiao Y, Anwar Z, Intrapiromkul J, et al. Patterns and implications of intracranial arterial remodeling in stroke patients. Stroke 2016;47: 434-40 CrossRef Medline

23. Lou X, Ma N, Shen H, et al. Noninvasive visualization of the basilar artery wall and branch ostia with high-resolution three-dimensional black-blood sequence at 3 Tesla. J Magn Reson Imaging 2014; 39:911-16 CrossRef Medline

24. Chimowitz MI, Kokkinos J, Strong J, et al. The Warfarin-Aspirin Symptomatic Intracranial Disease Study. Neurology 1995;45: 1488-93 Medline

25. Huang J, Degnan AJ, Liu Q, et al. Comparison of NASCET and WASID criteria for the measurement of intracranial stenosis using digital subtraction and computed tomography angiography of the middle cerebral artery. J Neuroradiol 2012;39:342-45 CrossRef Medline

26. Swartz RH, Bhuta SS, Farb RI, et al. Intracranial arterial wall imaging using high-resolution 3-Tesla contrast-enhanced MRI. Neurology 2009;72:627-34 CrossRef Medline

27. Maruyama H, Nagoya $\mathrm{H}$, Kato $\mathrm{Y}$, et al. Spontaneous cervicocephalic arterial dissection with headache and neck pain as the only symptom. J Headache Pain 2012;13:247-53 CrossRef Medline

28. Suzuki J, Takaku A. Cerebrovascular "moyamoya" disease: disease showing abnormal net-like vessels in base of brain. Arch Neurol 1969;20:288-99 CrossRef Medline

29. Fukui M. Guidelines for the diagnosis and treatment of spontaneous occlusion of the circle of Willis ('moyamoya' disease): Research Committee on Spontaneous Occlusion of the Circle of Willis (Moyamoya Disease) of the Ministry of Health and Welfare, Japan. Clin Neurol Neurosurg 1997;99(suppl 2):S238-40 Medline

30. Kuroda S, Houkin K. Moyamoya disease: current concepts and future perspectives. Lancet Neurol 2008;7:1056-66 CrossRef Medline

31. Scott RM, Smith ER. Moyamoya disease and moyamoya syndrome. N Engl J Med 2009;360:1226-37 CrossRef Medline

32. Gomes LJ. The role of imaging in the diagnosis of central nervous system vasculitis. Curr Allergy Asthma Rep 2010;10:163-70 CrossRef Medline

33. Hajj-Ali RA, Calabrese LH. Diagnosis and classification of central nervous system vasculitis. J Autoimmun 2014;48-49:149-52 CrossRef Medline

34. Kwak HS, Hwang SB, Chung GH, et al. High-resolution magnetic resonance imaging of symptomatic middle cerebral artery dissection. J Stroke Cerebrovasc Dis 2014;23:550-53 CrossRef Medline

35. Bley TA, Uhl M, Carew J, et al. Diagnostic value of high-resolution MR imaging in giant cell arteritis. AJNR Am J Neuroradiol 2007;28: 1722-27 CrossRef Medline

36. Choi CG, Lee DH, Lee JH, et al. Detection of intracranial atherosclerotic steno-occlusive disease with $3 \mathrm{D}$ time-of-flight magnetic resonance angiography with sensitivity encoding at 3T. AJNR Am J Neuroradiol 2007;28:439-46 Medline

37. Boussion N, Soulez G, De Guise JA, et al. Geometrical accuracy and fusion of multimodal vascular images: a phantom study. Med Phys 2004;31:1434-43 CrossRef Medline

38. Katsuno M, Kobayashi S. Diagnosis of vertebral artery dissection with basiparallel anatomical scanning magnetic resonance imaging. J Nippon Med Sch 2011;78:367-73 CrossRef Medline 